\title{
Choosing the right reference cohort for assessing outcome of venovenous ECMO
}

\author{
Alexander Supady ${ }^{1,2,3^{*}}$ (0, Paul M. Biever ${ }^{1,2}$, Dawid L. Staudacher ${ }^{1,2}$ and Tobias Wengenmayer ${ }^{1,2}$
}

Keywords: COVID-19, Extracorporeal membrane oxygenation, Patient selection

We thank Karagiannidis et al. for reporting important mortality data of COVID-19 patients supported with extracorporeal membrane oxygenation (ECMO) in Germany [1]. The mortality they reported was notably higher than in other large cohorts [2]. The data come from nationwide billing data of all hospitals in Germany; therefore, the risk of selection bias or underreporting of negative results is lower than in previous cohorts.

The authors argue against the unselective use of ECMO in patients who have a high risk of dying during the course of treatment. We agree that ECMO is an expensive and resource-intensive support option. Therefore, it should be used only in selected patients after careful risk-benefit evaluation. This assessment should take into account all available and relevant prognostic information and the (presumed) patient will. During the COVID-19 pandemic, the availability of trained medical staff and the utilization of available intensive care resources must also be taken into consideration [3].

Yet, one of the major difficulties in patient selection is to predict with sufficient accuracy the prognosis of individual patients. This is true for both patients with ECMO support and without. A more liberal use of ECMO in healthier patients who might have had a favorable outcome even without ECMO improves the survival probability attributed to the procedure, as does a restrained use in very sick and older patients who have a rather poor prognosis with or without ECMO (Fig. 1) $[2,4]$. However, in our view, the expansion of the scope of indications may nevertheless be justified or even warranted. This may be the case when experienced physicians base their decisions on a responsible bedside assessment of the individual patient and expect poorer outcome without the use of ECMO. This approach was recently described as "salvage ECMO" [5].

For a comprehensive appraisal of the role of ECMO for the treatment of severe respiratory failure, we believe that it is not sufficient to look at the survival rates of patients who eventually received ECMO. Instead, the entire cohort of invasively ventilated patients with defined severity criteria must be considered, including patients in whom ECMO was not chosen, both due to futility and based on the assessment that they will recover even without ECMO. Consequently, the approach that achieves the best overall outcome should be considered superior. This way may help us to offer each patient the optimal therapy and improve our algorithms for making decisions for or against the use of ECMO. original author(s) and the source, provide a link to the Creative Commons licence, and indicate if changes were made. The images or other third party material in this article are included in the article's Creative Commons licence, unless indicated otherwise in a credit line to the material. If material is not included in the article's Creative Commons licence and your intended use is not permitted by statutory regulation or exceeds the permitted use, you will need to obtain permission directly from the copyright holder. To view a copy of this licence, visit http://creativecommons.org/licenses/by/4.0/. The Creative Commons Public Domain Dedication waiver (http://creativeco mmons.org/publicdomain/zero/1.0/) applies to the data made available in this article, unless otherwise stated in a credit line to the data. 


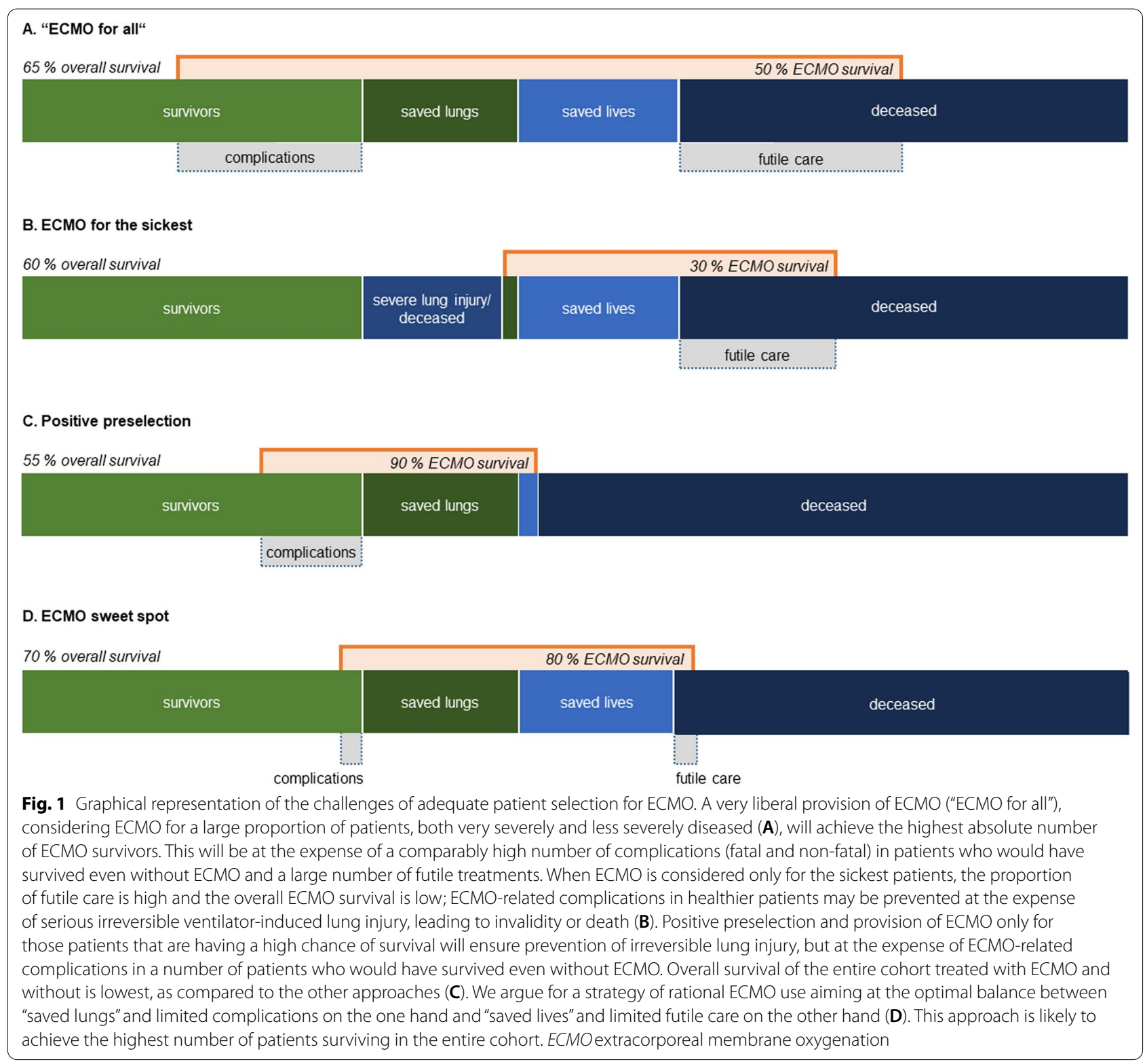

\section{Response to Supady et al.}

Thomas Bein ${ }^{4}$, Christian Karagiannidis, ${ }^{5,6}$, Steffen Weber-Carstens ${ }^{7}$, Arthur Slutsky ${ }^{8}$, Wolfram Windisch ${ }^{5,6}$ and Daniel Brodie ${ }^{9,10}$

\footnotetext{
${ }^{4}$ Faculty of Medicine, University of Regensburg, Regensburg, Germany ${ }^{5}$ Department of Pneumology and Critical Care Medicine, ARDS and ECMO Centre, Cologne-Merheim Hospital, Kliniken Der Stadt Köln gGmbH, Witten, Germany

${ }^{6}$ Herdecke University Hospital, Ostmerheimer Strasse 200, 51109 Cologne, Germany

${ }^{7}$ Department of Anesthesiology and Operative Intensive Care Medicine (CCM, CVK), Charité - Universitätsmedizin Berlin, Berlin, Germany ${ }^{8}$ Keenan Research Centre for Biomedical Science, Li Ka Shing Knowledge Institute, St Michael's Hospital, University of Toronto, Toronto, Canada ${ }^{9}$ Department of Medicine, Columbia University College of Physicians
}

and Surgeons, New York, USA

${ }^{10}$ Center for Acute Respiratory Failure, New York-Presbyterian Hospital, New York, USA

We thank Dr. Supady and colleagues for their thoughtful letter regarding the difficulty with divining who should be placed on ECMO based on our data demonstrating high mortality with the use of ECMO for COVID-19 in Germany [1]. Implicit in their argument is that declaring a mortality rate to be high or low requires that we know what mortality rate should actually be expected without the use of ECMO in COVID-19, an information that uncontrolled observational data cannot provide [6] . This is an important argument for conducting well-designed 
randomized clinical trials. However, absent such evidence, how should we proceed? Nonetheless, we believe that the overall mortality rate should be seen as high relative to the investment of resources, suggesting that the use of ECMO in this population may indeed be too liberal.

One further point that merits discussion is that, while Supady et al. use the term "selection" regarding the decision to implement ECMO, we prefer the term "indication." Indication is based on the careful assessment of the realistic rehabilitation potential of the patient in association with a given intervention (e.g., ECMO) to allow the patient to resume a reasonable quality of life and to achieve a well-defined therapeutic goal in concert with the goals and values of the individual patient [7]. This concept also aims to balance benefit (survival) against harm (invasive treatment, pain, sedation, immobilization and the psychological burden on surrogates). Therefore, the indication for ECMO should be based on several anamnestic, demographic, medical and prognostic parameters in each individual patient to avoid futile treatments as well as high in-hospital mortality. We agree with Dr. Supady's framing of the balanced and rational use of ECMO; however, the reality in Germany-as expressed in our letter-shows that we are far from the rational use of ECMO. This has also been clearly emphasized by a recent paper showing that $40 \%$ of ECMO cases in Germany are performed in hospitals with 2 or fewer cases per year [8] with no assurances regarding the quality of ECMO delivery, which may reasonably be expected to contribute to high mortality.

For these reasons, we are confident that the high mortality rate in German ECMO patients reflects an opportunity to insist on a more rational ECMO application, to reflect both on the organizational approach to its use and on the indications that should be broadly acceptable.

\section{Acknowledgements}

None.

\section{Authors' contributions}

AS designed the paper and prepared the first draft based on preceding discussions with all co-authors. All authors reviewed the draft and approved the final version of the manuscript.

\section{Funding}

None.

Availability of data and materials

Not applicable.

\section{Declarations}

Ethics approval and consent to participate Not applicable.

Consent for publication

Not applicable.
Competing interests

The authors declare that they have no competing interest.

\section{Author details}

${ }^{1}$ Department of Medicine III (Interdisciplinary Medical Intensive Care), Medical Center - University of Freiburg, Faculty of Medicine, University of Freiburg, Hugstetter Strasse 55, 79106 Freiburg, Germany. ${ }^{2}$ Department of Cardiology and Angiology I, Heart Center, University of Freiburg, Freiburg, Germany. ${ }^{3}$ Heidelberg Institute of Global Health, University of Heidelberg, Heidelberg, Germany. ${ }^{4}$ Faculty of Medicine, University of Regensburg, Regensburg, Germany. ${ }^{5}$ Department of Pneumology and Critical Care Medicine, ARDS and ECMO Centre, Cologne-Merheim Hospital, Kliniken Der Stadt Köln gGmbH, Witten, Germany. ${ }^{6}$ Herdecke University Hospital, Ostmerheimer Strasse 200, 51109 Cologne, Germany. ${ }^{7}$ Department of Anesthesiology and Operative Intensive Care Medicine (CCM, CVK), Charité - Universitätsmedizin Berlin, Berlin, Germany. ${ }^{8}$ Keenan Research Centre for Biomedical Science, Li Ka Shing Knowledge Institute, St Michael's Hospital, University of Toronto, Toronto, Canada. ${ }^{9}$ Department of Medicine, Columbia University College of Physicians and Surgeons, New York, USA. ${ }^{10}$ Center for Acute Respiratory Failure, New York-Presbyterian Hospital, New York, USA.

Received: 7 December 2021 Accepted: 14 December 2021

\section{References}

1. Karagiannidis C, Slutsky AS, Bein T, Windisch W, Weber-Carstens S, Brodie D. Complete countrywide mortality in COVID patients receiving ECMO in Germany throughout the first three waves of the pandemic. Crit Care. 2021:25(1):413.

2. Barbaro RP, MacLaren G, Boonstra PS, Combes A, Agerstrand C, Annich G, Diaz R, Fan E, Hryniewicz K, Lorusso R, et al. Extracorporeal membrane oxygenation for COVID-19: evolving outcomes from the international Extracorporeal Life Support Organization Registry. Lancet. 2021;398(10307):1230-8.

3. Supady A, Badulak J, Evans L, Curtis JR, Brodie D. Should we ration extracorporeal membrane oxygenation during the COVID-19 pandemic? Lancet Respir Med. 2021;9(4):326-8.

4. Supady A, Taccone FS, Lepper PM, Ziegeler S, Staudacher DL. Group CO-S: survival after extracorporeal membrane oxygenation in severe COVID19 ARDS: results from an international multicenter registry. Crit Care. 2021;25(1):90.

5. Abrams D, Ferguson ND, Brochard L, Fan E, Mercat A, Combes A, Pellegrino V, Schmidt M, Slutsky AS, Brodie D. ECMO for ARDS: from salvage to standard of care? Lancet Respir Med. 2019:7(2):108-10.

6. MacLaren G, Fisher D, Brodie D. Treating the Most Critically III Patients With COVID-19: The Evolving Role of Extracorporeal Membrane Oxygenation. JAMA. 2022;327(1):31-2. https://doi.org/10.1001/jama.2021.22580.

7. Beauchamp T, Childress J. Principles of biomedical ethics. Oxford: Oxford Press; 2001

8. Bercker S, Petroff D, Polze N, Karagianidis C, Bein T, Laudi S, Stehr SN, Voelker MT. ECMO use in Germany: an analysis of 29,929 ECMO runs. PLoS ONE. 2021;16(12):e0260324.

\section{Publisher's Note}

Springer Nature remains neutral with regard to jurisdictional claims in published maps and institutional affiliations. 